\title{
Implicaciones epistémicas del pensar histórico desde la perspectiva del sujeto
}

\author{
Hugo Zemelman
}

Una de las implicaciones más significativas del pensar histórico es la potenciación del sujeto. Si la perspectiva asumida va en consonancia con la atención de la demanda de cambio que la realidad nos plantea, éste será un pensar histórico que busque reconocer lo necesario históricamente, que rompa los límites en busca de lo inédito. Los sujetos se tornan punto de referencia para darle sentido y dirección a su acción, de acuerdo con las posibilidades de desenvolvimiento y en función del proyecto desde donde se leen las potencialidades, entre otras, las implicaciones epistémicas del acto de pensar, para un sujeto situado histórica y políticamente.

PALABRAS CLAVE: potenciación, pensar histórico, necesidad, movimiento del sujeto, conciencia histórica

The Epistemic Implications of Historical Thinking from the Perspective of the Subject

One of the most significant implications of historical thinking is the empowerment of the subject, assuming as a prospect for change to meet the demand posed by the reality. Then it will recognize what is historically necessary, and breaking-off the limits in search on the unpublished thing. Becoming the historical reference point to think of subjects to give meaning and direction to their actions, according to the possibilities of development and depending on the project from which the potentials are read. Will the potential, among others, the epistemic implications of the act of thinking, for a subject historically and politically situated.

KEYWORDS: empowerment, historical thinking, necessity, re-positioning of the subject, historical consciousness

Hugo Zemelman: Estudios Epistémicos e Histórico-culturales, "Instituto Pensamiento y Cultura en América Latina", A. C.

México, Distrito Federal

ipecal_mexico@yahoo.es

Desacatos, núm. 37, septiembre-diciembre 2011, pp. 33-48

Recepción: 12 de marzo de 2011 / Aceptación: 26 de abril de 2011 


\section{INTRODUCCIÓN}

$\mathrm{E}$ $n$ una época en que la necesidad de trascendencia moral y el deseo de aventurarse se pierde cada vez más, en que la voluntad de atreverse se debilita y se limita al espacio de la eficacia que proporciona reconocimiento, en que es difícil hablar y apostar por la potenciación de las personas, en que soñar se ha reducido a éxito y éste a logros materiales, nuestro desafío es aprender de las experiencias para cambiar cuando las circunstancias lo impongan y liberarnos de los miedos y de las pequeñeces, sin perder la visión de humanidad que le da su significado único a la condición del hombre. Las reflexiones que siguen obedecen a este espíritu: ir más allá de lo alcanzado, con todos y a pesar de muchos, construir caminos que nos llevan a vislumbrar nuevos misterios que son a su vez nuevos renaceres.

El pensar histórico busca reconocer los espacios en los que se distingue la presencia de lo históricamente necesario, aunque al mismo tiempo es una construcción desde la toma de conciencia de la disconformidad respectodelascircunstancias. Esta disconformidad constituye un requisito para enfrentar las inercias, personales o sociales, pues representa la base de cualquier acto de resistencia para enfrentar lo que excede los límites de una situación dada. El pensar histórico equivale a interpretar la disconformidad como una alerta frente a lo excedente, transformar lo reconocible o la simple constatación empírica en necesidad de nuevas preguntas que sean un puente para transitar desde la disconformidad hacia el problema que está en el fondo.

En consecuencia, el pensar histórico es la capacidad de complementar el simple acto de pensar circunscrito a los marcos de la predicación de objetos, es el rompimiento de los límites en la búsqueda de lo inédito. Colocarse ante las circunstancias es la disposición y capacidad para desplegarse conforme a un sentido, un para qué, que influye sobre la construcción de conceptos en torno a la realidad externa. Significa romper con los contenidos ceñidos a los límites para dar cuenta de lo real como espacio de sujetos: pensar desde el momento que obliga a hablar también de sus aperturas, lo que alude al movimiento de lo producido como siendo lo constituyente de éste y que transformamos en el ángulo para considerar el momento sin restringirnos a sus estructuras cerradas. De ahí que cuando hablamos de inconformarnos con una situación suponemos verla en sus posibilidades de desenvolvimiento, que requieren la presencia del proyecto desde el cual se leen y determinan sus potencialidades.

Por ello el movimiento del sujeto reviste importancia, porque es el que permite plantear el distanciamiento respecto de lo dado, en la medida en que se plantea el ajuste o desajuste entre las dinámicas de la subjetividad y sus circunstancias. Es lo propio de la autonomía del sujeto en relación con las condiciones que lo conforman: sus inercias, los estereotipos, los rutinismos, los mecanismos de compensación social, etc. En síntesis, no quedar ceñido a los atributos sociales. De ahí la relevancia de algunas categorías o formas epistémicas de pensar, como la colocación en el momento histórico o concebir el momento como una articulación dinámica. La apertura respecto de los límites de lo dado que conforman modos epistémicos del pensar histórico también supone la compleja relación con dinamismos psicológicos - por ejemplo, percepción psico-cultural- que pueden ser de apoyo o inhibitorios porque constituyen la base que define el marco en el que se desenvuelven los mecanismos operativos del pensar histórico. Nos recuerda la necesidad de reconocer que, como señalara Nietzsche, "entre los servidores de lo evidente y los solitarios, están los combatientes, es decir, quienes están henchidos de esperanza” (Nietzsche, 2010: 23). Pensamos en esos hombres que por vivir históricamente no pueden "acostumbrarse a establecer el valor de todas las cosas en función del ahorro o de la pérdida de tiempo..., que no han olvidado todavía pensar, cuando leen" (Nietzsche, 2010: 28).

Es preciso encarar y resolver el problema metodológico del pensar histórico desde dos planos: el formal-categorial de lo epistémico y el que definen las subjetividades psico-culturales, ya que hacen las 
veces de puertas de entrada para concebir el método como una postura racional. Nos encontramos ante la necesidad de abrirnos a lo no dado, comparable con la necesidad del caminante de encontrarle sentido al camino cuando lo vislumbra desde el paisaje por el que atraviesa. En ese momento se genera la tensión que alimenta la necesidad de orientarnos entre el andar mismo, tal como está forjado por el lenguaje en su forma de estructurar la mirada y el pensamiento, y los desafíos externos a éste.

¿Qué es lo que está más allá de lo que no puede significarse con un nombre claro de identidad pero que exige ser nombrado? ¿Cómo decir aquello que para que tenga presencia requiere romper con las formas inteligibles, acabadas y aceptadas? ¿Cómo decir lo que reclama ser significado pero nunca puede serlo porque el significado lo diluye? Aquí se plantea el discurso no centrado en predicados sino en verbos. ¿Cómo puede pensarse en un lenguaje propio del pensamiento social la atmósfera brillante de Pedro Páramo de Rulfo, de Machu Picchu de Neruda, de la pintura de Matta? ¿Cómo leer "socialmente" la danza y folklore del continente? ¿Cómo leer esas realidades en el discurso de la esperanza? ¿Cómo hacer de la ética un componente de un pensamiento que piense a través de muchos lenguajes? El problema que nos ocupa son los desafíos que representa el movimiento del sujeto históricamente situado.

\section{EL SUJETOY LA FORMA DEL PENSAR HISTÓRICO}

La incorporación del sujeto a su propio discurso supone no reemplazarlo por un predicado en el que deja de ser real para ser solamente gramatical. Parte de esa tradición del pensamiento, teñida por el "inmaterialismo platónico y por el trascendentalismo judeo-cristiano", dificulta que "pueda ser convincentemente purgado de su registro metafísico" (Steiner, 1999: 22). El desafío radica en recuperar el lugar del hombre, lo insondable del hombre como hombre, en forma que pueda estar en "las altas cumbres ocupadas ilícitamente - según Heidegger - por la onto-teología y la metafísica" (Steiner, 1999: 23).

Abordar el sujeto significa no otorgarle el rango de señor soberano de la naturaleza, sino reconocer su historicidad antes que limitarse a rescatar una voluntad de poder en tanto "subjetividad que se ve seriamente exaltada", como ha sido analizada por Nietzsche (Steiner, 1999: 143). Tampoco significa quedarse en las concepciones referidas "de nuevo al observador humano", como en Descartes, para quien "el cogito va antes del sum" (Steiner, 1999: 142), ni refugiarse en reduccionismos como el de "sumergirse en la plenitud del estado de ahî" (Steiner, 1999: 29).

Nos ocupan los desafíos que representa para el lenguaje el movimiento del sujeto históricamente situado. Pretendemos abordar el problema desde la lógica de potenciación. Vivimos una crisis de las legaliformidades que obliga a encontrar nuevas formas de construcción del conocimiento congruentes con los retos que se desprenden de concebir la realidad socio-histórica como una construcción. Vinculamos esta construcción con la categoría de lo necesario como "concepto central del pensamiento dialéctico basado en la categoría de totalidad... la necesidad [que] libera al espíritu del estado de congelamiento en que el entendimiento limitado mantiene sus contradicciones" (Bloch, 1983: 118). Aunque esta liberación es concebible solamente a partir de sostener que "el espíritu es un producto del proceso histórico" (Adorno, 1984: 75) que se corresponde con la idea de que el yo real reconoce "la sucesión temporal por condición de su posibilidad y [...] ésta sólo es posible como la de algo temporal" (Adorno, 1984: 141). De lo que se desprende que la necesidad supone "la negación de lo devenido" (Bloch, 1983: 119), en tanto espacio del devenir. No obstante, la negación "dejada por completo a sí mismo [...] no tiene por qué sentirse forzado al progreso" (Bloch, 1983: 119).

La necesidad se vincula con el movimiento inherente de las cosas, por cuanto "es la negación de lo inválido, del callejón sin salida, de lo aislado en sí" (Bloch, 1983: 126), por lo mismo refiere al "triunfo 
de lo nuevo", "la necesidad de lo jamás ansiado, jamás realizado por el mundo existente". Es el "acecho al objeto mismo en su desarrollo" (Bloch, 1983: 137), ya que "es elemento móvil, y sólo él", lo que fluye - el pantha rei de Heráclito-, lleva a tener que "aceptar el reto de lo históricamente existente como [...] objeto" (Adorno, 1984: 185).

Desde esta línea, es impresionante constatar las anticipaciones que se han hecho de esta categoría del pensamiento, ${ }^{1}$ aunque lo más notable sea la función que se le asigna como articuladora de diferentes formas de creación, ya que está presente en distintos lenguajes del hombre. "La creación artística es obra de la fantasía, pero de una fantasía exacta, que, tal como hace la ciencia, descubre en lo visible la oculta necesidad interior que la gobierna" (Mondolfo, [1954] 2004: 17). Esa necesidad puede reconocer racionalmente muchas opciones de realización en la medida en que no se agota en ninguna configuración preestablecida. De ahí que lo necesario requiere de una postura más inclusiva que el razonamiento circunscrito a las determinaciones (Bruno, citado en Mondolfo, [1954] 2004: 67). ${ }^{2}$ La forma del pensar histórico puede ser una solución porque representa un cambio en el punto arquimédico de apoyo del pensar científico cuando plantea exigencias de objetivación que no se res-

\footnotetext{
${ }^{1}$ Es el caso de Leonardo Da Vinci, como recuerda Mondolfo. Leonardo habla de "la necesidad [...] maestra y tutora de la naturaleza... ¡Oh, admirable necesidad! Tú, con suma razón, obligas a todos los efectos a participar de sus causas, y con suma e irrevocable ley cada acción natural te obedece mediante una brevísima operación" (Mondolfo, [1954] 2004: 31).

${ }^{2}$ A este respecto vale la pena recordar la idea de método que planteara Giordano Bruno como postura racional, mucho antes que Francis Bacon, en su lucha sin concesiones contra la ignorancia, el prejuicio, el dogma y la intolerancia: "nunca debe valer como argumento la autoridad de cualquier hombre, por excelente e ilustre que sea... es sumamente injusto plegar el propio sentimiento a una reverencia sumisa hacia otro; es digno de mercenarios o esclavos y contrario a la dignidad de la libertad humana sujetarse y someterse; es suma estupidez creer por costumbre inveterada; es cosa irracional conformarse con una opinión a causa del número de los que la tienen... hay que buscar, en cambio, siempre una razón verdadera y necesaria... y escuchar la voz de la naturaleza" (Bruno, citado en Mondolfo, [1954] 2004: 67).
}

tringen al principio de identidad, ni al manejo del tiempo lineal y determinista, para el que la realidad conforma espacios de posibilidades. Por tanto, el movimiento de lo necesario reviste la calidad de forma de razonamiento.

\section{EL MOVIMIENTO DE LO NECESARIO COMO FORMA}

El pensar histórico demanda el reconocimiento de los procesos heterogéneos que lo constituyen. Esto exige partir de la capacidad de los sujetos para construir realidades. El desafío es avanzar de los hombres a sus ideas, de las ideas a la conciencia y desde la conciencia a la conducta individual y socialmente organizada. Se pone en juego la capacidad de reconocer opciones y decidir sobre las que permitan dar cuenta de la historia como necesidad compartida, sin perder al individuo en la historia, y se enfrenta un ejercicio epistémico-metodológico concordante con la categoría de la práctica consciente de la historicidad y de los desafíos que plantea para el auto-crecimiento del sujeto. En consecuencia, pensar lo real histórico-social desde lo necesario rompe con los razonamientos apegados a las formas de las determinaciones, pues plantea la necesidad de la inclusividad — que obliga a reflexionar desde horizontes- entre niveles en que lo real se plasma.

En este sentido, el pensar histórico se encuentra en la antípoda de la tradición metafísica de Occidente, pero también se enfrenta con los extravíos que resultan de las desviaciones objetivizantes de la ciencia, que han terminado por configurar una subordinación del sujeto respecto de la estructura de los enunciados atributivos de propiedades, porque el pensar histórico no puede disociarse de la activación de lo real como ocurre con el pensamiento metafísico y su obsesión por la esencia, y con el propio cientificismo y sus deformaciones tecnocráticas que subordinan al sujeto concreto.

En efecto, el afán de objetividad desarraiga al hombre reforzado por mecanismos como "la cosificación, 


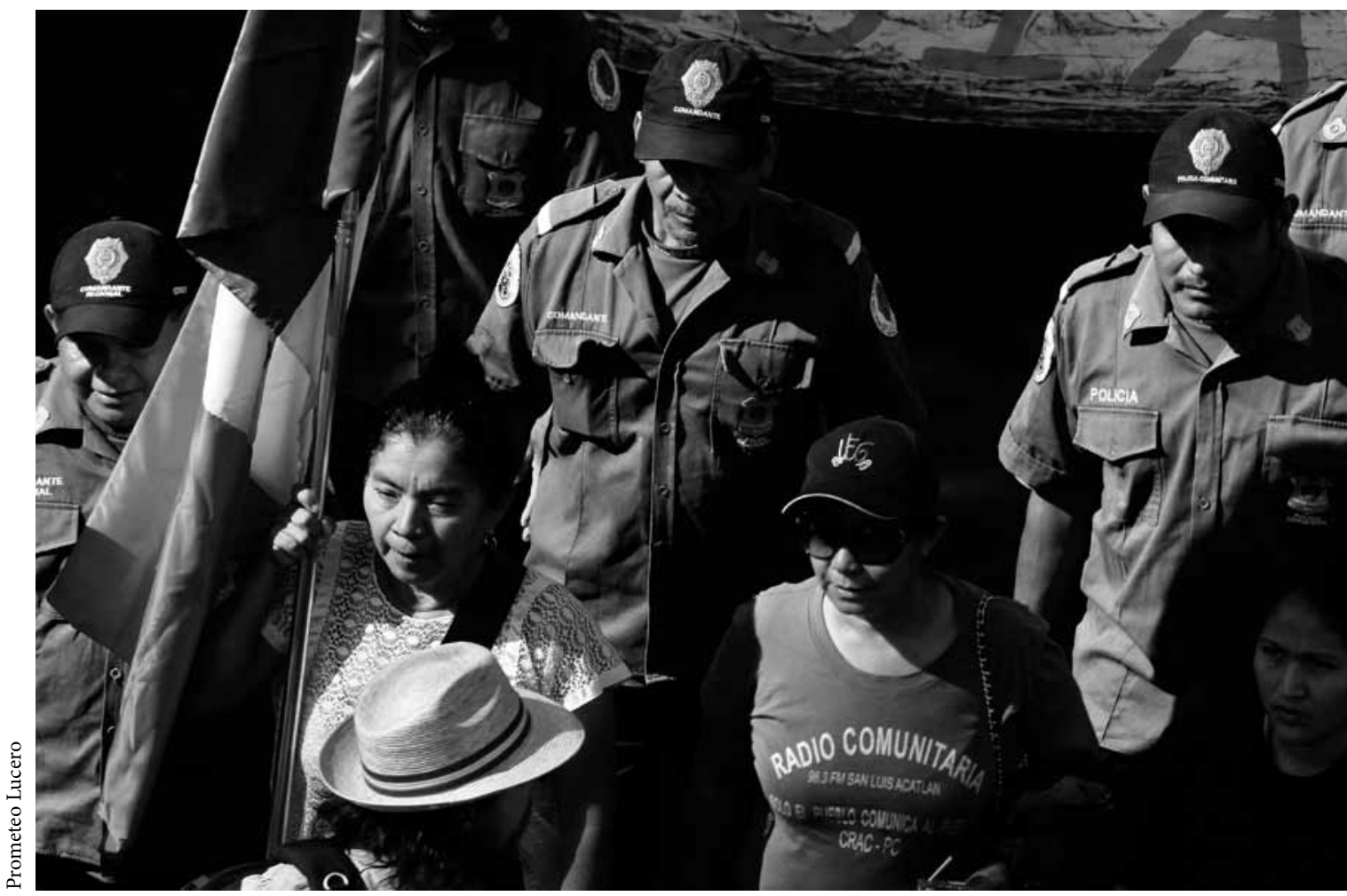

Policía comunitaria en la ciudad de México durante la Marcha Nacional por la Paz, 8 de mayo de 2011.

enajenación, unidimesionalidad" (Steiner, 1999: 153). Más bien, nos planteamos incorporar al sujeto como parte de aquello que construye cuando pone en juego sus potencialidades, como "aquel acicate que... estimula a avanzar siempre más allá de lo que posee" (Mondolfo, [1954] 2004: 76). Como lo ha dicho el poeta: "prosternaos vosotros los que no habéis pisado jamás el horizonte" (Huidobro, 2002: 29). De esta manera, pensar se vincula con el autocrecimiento en forma de "hacerse cargo [...] de la enorme situación de expósito del hombre en el abrir, en esa delgada apertura de su espacio de libertad que el todo ordenado del cielo natural se permite al querer y al poder humano" (Gadamer, 2001: 126). La idea trasciende a la objetividad-objeto en cuanto "comprensión inmediata por lo que el hombre se intenta hacer un hogar en el mundo" (Gadamer, 2001: 128), por ello el pensar histórico procura hacerse cargo de estos desafíos para, de ese modo, recuperar al hombre desde la tensión entre lo advenido y lo que puede advenir.

Siguiendo a Castoriadis (2002), el hombre antes de deducir tiene la facultad de crear - se puede justificar pero no fundamentar-, lo que lleva a colocar en el centro del debate a las formas de razonamiento que puedan dar cuenta de las condiciones de posibilidad de las emergencias, antes que a la deducción. Pero para abordar este cambio en la relación entre pensamiento y lenguaje, y dar cuenta de la compleja relación entre el movimiento del sujeto y las formas del discurso, debemos reemplazar la exigencia de verdad por la de colocación ante el momento, como relación de conocimiento que excede los límites de una simple premisa lógica-epistémica, en la medida en que representa la necesidad de horizontes con posibilidad de objetos construibles.

En consecuencia, la relación entre objetividad y mundo se funda en la necesidad de sentido del mismo 
sujeto, ya que no puede provenir de algo ajeno a éste sino desde su propio movimiento, más aún, de su apetencia por lo nuevo. Como señalara Heráclito, "si uno no espera, no encontrará tampoco lo inesperado" (fragmento 18, citado en Gadamer, 2001: 67). También lo acota el mismo pensador: "es gracias a la esperanza que lo que aparece, precisamente porque era imprevisible y parecía inalcanzable, pudo presentarse el modo totalmente diferente a lo que se esperaba... sólo al que tiene esperanza se le puede enviar lo inesperado" (Gadamer, 2001: 67). En este marco, recordemos a Bloch cuando habla del "descubrimiento de lo todavía no consciente o crepúsculo hacia delante", en particular cuando plantea, al rescatar lo nuevo desde la juventud, su idea de "la alborada, lo esperado, la voz del mañana... la época en flor... repleta de amaneceres hacia delante..." (Bloch, 2004: 151), y que refuerza el planteamiento heracliteano reconociendo que "lo propio del alma es la razón universal que se aumenta a sí mismo" (nota 40, Bloch, 2004: 148).

La colocación es central a lo necesario, pero no a lo causal. Nos ubicamos ante un horizonte de opciones que no se encuadra en la organización de contenidos disciplinarios, sino, más bien, los incluye como los contenidos propios de las lógicas de objetos. La necesidad descansa en el momento, pero también en un distanciamiento respecto de éste, porque es la concreción de una secuencia. El acto de pensar desde la necesidad lo es tanto de lo dado como de la acción, aunque no como proyección sino como potencialidad que puede asumir distintas direcciones. Por último, la organización del pensar histórico alude a las coordenadas del sujeto que no pueden ser ajenas a la naturaleza de los referentes colectivos que le sirvan de marco de referencia: familia, comunidad de pertenencia, unidad productiva, etnia, clase, región. ${ }^{3}$ Su importancia consiste en

\footnotetext{
${ }^{3}$ La importancia de esta relación reside en que la naturaleza del nucleamiento de lo colectivo cumple las funciones de mediación que transforma la subjetividad individual en social, lo que se traduce en mayor o menor capacidad de autonomía en el acto de pensar y de decidir, por consiguiente, de la construcción social que el sujeto es capaz de impulsar.
}

que pueden ocurrir situaciones estructuradas que se abran a posibles inclusiones de otros planos estructurados, como la relación familia-comunidad o comunidad-clase, etc., de manera que se complejiza el punto de partida del pensamiento y su construcción de conocimiento.

\section{FACULTADES DEL SUJETOY PENSAR HISTÓRICO}

El tránsito hacia lo no devenido para reconocer lo potenciable supone reemplazar la exigencia genético-causal por la tensión presente-futuro que resuelve el reconocimiento de lo potenciable diferenciándola de lo puramente probabilístico o previsible. Esto se corresponde con la consideración de la capacidad de construcción de realidades, como espacios de relaciones, trascendiendo la lógica de proposiciones asertivas a partir de un lenguaje que pueda potenciar al sujeto transformando la necesidad de sentido en ideas.

En este marco, no se puede ignorar la necesidad de articular diferentes lenguajes, como tampoco la relación, en lo que respecta al sujeto, entre cuerpo y pensamiento, en la medida en que la rigidez de aquél puede reflejarse en la rigidez del otro. A contrario sen$s u$, el movimiento del cuerpo puede contribuir a organizar un pensamiento abierto, siempre que la colocación en el momento no sea resultado de un acto puramente intelectual. Lo importante es entender que la historia siempre comienza siendo una experiencia, y por lo mismo se plantea la transformación del relato en discurso, o de no oponerlos, a fin de impedir que "las significaciones alienadas, estereotipos ideológicos" no subordinen la conciencia humana a la estructura y el espacio estructurante (Marty, 2007: 180).

Pensar desde el momento como espacio de posibilidades significa colocarse en el núcleo de la vinculación entre el movimiento de la externalidad y el movimiento del propio sujeto. Mientras el primero se concreta en una articulación de elementos heterogéneos, sometidos a diferentes tiempos y espacios, el movimiento del sujeto refiere a distintos 
planos de la subjetividad: sus necesidades, experiencias, posturas valóricas e ideológicas, conceptualizaciones, apetencias de futuro, etc. Algunos de estos elementos dan cuenta de regularidades, otros se remiten a lo aleatorio, aunque todos configuran un modo de razonamiento que trasciende las bifurcaciones clásicas entre caminos, que ha llevado a descartar al que no garantiza lo claro y consistente, como ha ocurrido desde Parménides a Descartes, y que se prolonga hasta nuestros días.

Tenemos la necesidad de transitar un camino sin garantía de luz y coherencia, hacia realidades inestables y problemáticas no vinculadas a causas claras. En palabras de Berger, situaciones en las que "existen conexiones ocultas y un orden oculto debajo de la casi infinita abundancia de un mundo empírico" donde las "realidades subyacentes irán develándose de todos modos", lo que puede estar exigiendo un método "quizás podría designarlo como un método barroco" (Berger, 1999: 12). La verdadera dificultad que presenta esta complejidad tiene que ver con las exigencias de construcción de conocimiento según la relevancia que tengan las facultades del sujeto, con sus respectivos lenguajes categoriales. ${ }^{4}$

\footnotetext{
${ }^{4}$ En relación con esta discusión, cabe formular una reflexión en torno a la relación entre verdad de objeto versus la exigencia de potencialidad en el marco de horizontes del pensamiento alternativo: "Nietzsche preguntó: ¿por qué hemos preferido lo verdadero a lo no verdadero (o a la incertidumbre, o a la ignorancia)?... Se atreve a cuestionar el valor de la verdad, pero sin salir de su referencia, permanece centrado en ello y no pone en tela de juicio el monopolio que la verdad impuso al pensamiento. Desde el punto de vista de la sabiduría, la pregunta sería: ¿cómo ha sido posible (y era necesaria) esta fijación con la verdad?" (Jullien, 2001: 110). Discusión que sale al paso a la tendencia que "no ve en el universo más que un conjunto dispar unificado sólo por el método, es decir, por las relaciones lógicas": tendencia que responde a una larga trayectoria en el pensamiento de Occidente que ha mostrado "cómo el esfuerzo filosófico ha vaciado [la noción de causa] de todo rasgo sustancial", pues el modelo de esta unidad centrado en el método supone un "reduccionismo al común denominador... [que]... sigue siendo el cogito" (Jullien, 2001: 47), pero que en el siglo xx enfrenta "el contragolpe, la reacción, de esta total subversión epistemológica que descubre que el de coherencia que era la razón no es más que una etapa aristotélica y cartesiana..." y que se relaciona con la negación de los principios de identidad y de determinación (Durant, 1999: 63).
}

La disposición del sujeto para potenciarse - hacia arriba - plantea la articulación de esas facultades para dar lugar a una praxis significativa. Los desafíos de conocimiento afectan a las distintas facultades, por separado o en su conjunto, mediados por conceptos diferentes, pues lo real se concreta mediante ajustes o disociaciones entre estímulos epistémicos y las capacidades psicológicas del sujeto para dar cuenta de ellos. Estos desafíos pueden referirse a la capacidad analítica del sujeto o bien a su imaginación, a su voluntad y a su capacidad para la acción, de modo que puede ser autónomo y sostener posturas axiológicas o ideológicas ante el futuro desde un sentido de historia. Los desafíos de conocimiento mediados por mecanismos psico-cognitivos o psicognoseológicos, como abstracciones analíticas -imágenes, símbolos o metáforas-, contribuyen a conformar el acto de pensar desde su raíz. En consecuencia, el acto de pensar como tal refleja una postura de autonomía del sujeto que se traduce en definir un "ante" que lo distancie de la inmediatez de las circunstancias. El "ante" al que nos referimos constituye un ángulo de pensamiento que articula planos especificables de conocimientos, de ahí que el acto de pensar consista en la capacidad para colocarse en el momento-secuencia que cumple la función de parámetro orientador para la construcción de conocimiento. En este sentido, se plantea un doble desafío: determinar las categorías propias del movimiento del sujeto y las que dan cuenta del momento, tanto en su articulación interna de niveles, como en la apertura hacia su propio desenvolvimiento.

La conciencia de la historicidad conjuga ambas exigencias: no versa sobre ningún contenido $u$ objeto, sino sobre lo pertinente al ángulo desde el que se construye una relación incluyente de conocimiento. ${ }^{5}$ Por eso, la colocación involucra a todo el sujeto para avanzar hacia horizontes rechazados por el discurso

\footnotetext{
${ }^{5}$ El planteamiento sobre el movimiento del sujeto puede resumirse de la siguiente manera: el sujeto se relaciona con su contexto - sus circunstancias - mediando su capacidad de autonomía que se caracteriza por la capacidad para colocarse ante las circunstancias como espacio de posibilidades.
} 


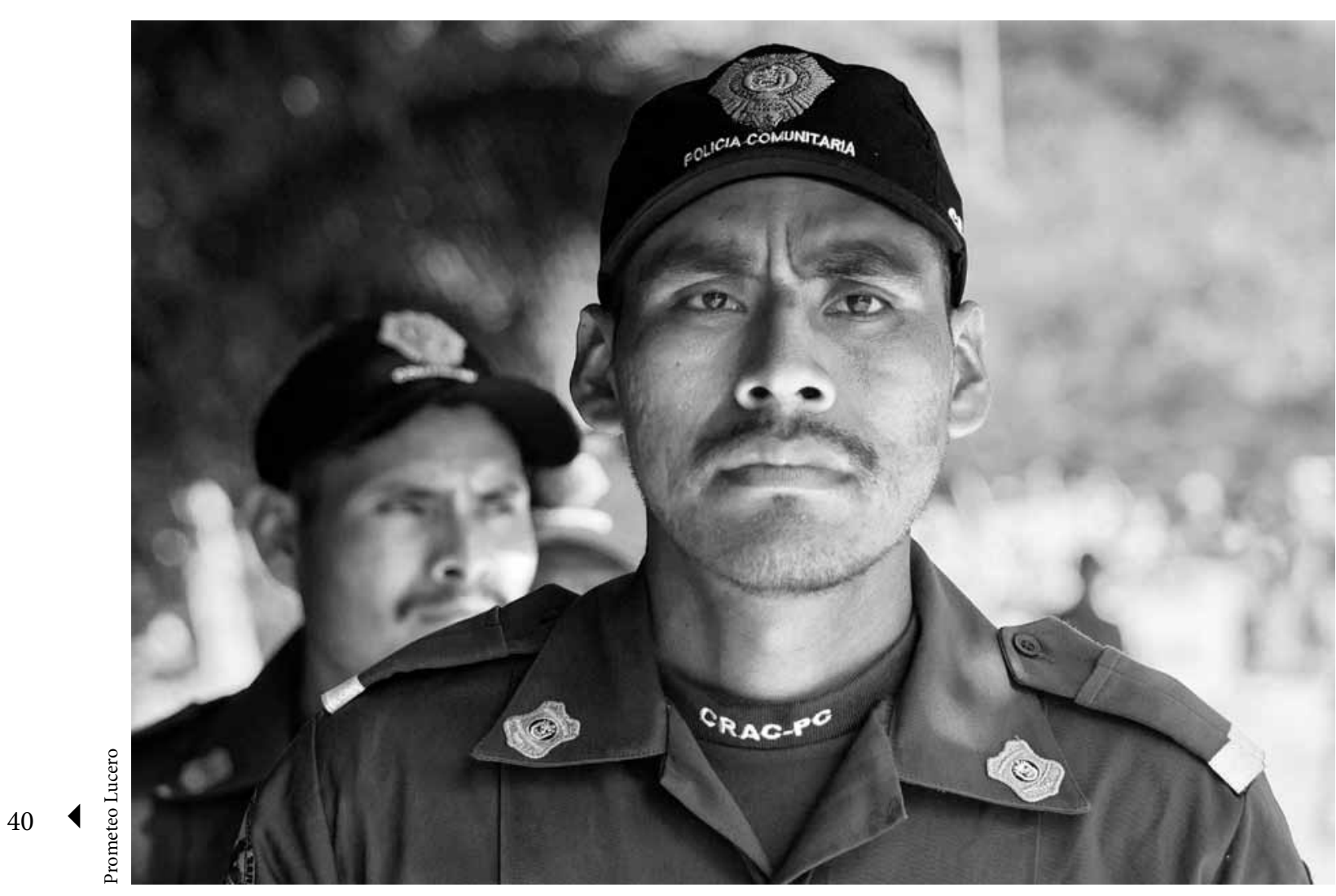

Desfile del aniversario de la Policía comunitaria, San Luis Acatlán, octubre de 2010.

dominante - por la economía política de la verdad para decirlo en términos de Foucault-, pero también puede vislumbrarse lo rechazado, pudiendo tomar conciencia en lo inédito, aunque todavía no puede nombrarlo. Estamos:

situados en el límite que ha permitido llegar a un paradigma teórico, como el marxista, y ante la irrupción de nuevos fenómenos y situaciones problemáticas, cuya aprehensión requiere de ajustes en las estructuras categoriales, en el marco básico que exige comprender la realidad para transformarla (Zemelman, 1989: 28).

Nuestros problemas residen en captar el presente susceptible de potenciación por la práctica social, lo que nos enfrenta al tránsito de la relación presente-pasado a la de presente-futuro, situación en la que el conocimiento se plantea "no [como] reconstrucción de lo devenido, sino como apropiación del futuro", es decir, "aquello no devenido, lo virtual de la realidad" (Zemelman, 1989: 28-29). En lo propio del quehacer político. En lo expuesto está presente el hombre-proyecto en lugar del hombre entelequia, o el hombre agónico como encarnación del desafío de acciones con sentido o de búsqueda de sentidos que no puede restringirse a una forma de conciencia limitada a objetos en la medida en que se relaciona con la conciencia abierta a planos de realidad compartidos por una multiplicidad de sujetos. En suma, se busca recuperar lo humano desde la historia. Pero ¿cuál es la influencia que tiene este movimiento en la construcción del conocimiento? ¿Cuáles son las consecuencias 
que tiene el conocimiento sobre el movimiento del sujeto? ${ }^{6}$

\section{CONTENIDOSY MÉTODOS}

El momento como articulación desde la que pensamos nos obliga a estar en estado de alerta ante los contenidos que no se ajustan fácilmente a las exigencias centradas en la explicación científica en la que predomina el esfuerzo por destacar un factor que, en tanto dominante, sirva para dar cuenta de una variedad de situaciones previsibles. El antiguo concepto griego de método vuelve a tomar su lugar como el "camino de la relación objetiva a lo que debe conocerse", cuya medida se obtiene de su "adecuación... en función de la peculiaridad del ámbito investigado" (Gadamer, 2001: 83), en contraposición con el método de Descartes como un "acercamiento universal" con "exclusión del error", lo que es posible partiendo del "mantenimiento de las condiciones formales del proceder metódico" (Gadamer, 2001: 83) que responde al predominio del camino de apertura a lo nuevo, inesperado e inédito, siempre que no se agote en condiciones formales que someten el pensar a exigencias que lo mantienen rígido. Lo central de la reflexión epistémico-metódica es romper con los límites de lo sabido y lo observado, a fin de construir el conocimiento en forma de vislumbrar lo nuevo y emergente (Gadamer, 2001: 82).

\footnotetext{
${ }^{6}$ Lo que plantea como cuestión metodológica, y no ética, querer ser sujeto, que se expresa en la capacidad para reconocer espacios de autonomía para, desde éstos, reconocerse con posibilidades de despliegue. Pero recuperarse para el despliegue, no como un mínimo zoologizado, sino como micro-espacios hacedores de macro-espacios incluyentes, cuestión que hace del despliegue parte de la problemática para gobernarse a sí mismo desde la necesidad y disposición para reconocer opciones. Todo lo cual remite a la cuestión del ethos, ya anticipado por Heráclito, para quien "el poder de las ilusiones que cada uno tiene sobre sí mismo, igual que ver correctamente el destino humano, no está troquelado por la guía de un daimon, sino por la guía que uno lleva de su propia vida (ethos)" (Gadamer, 2001: 27).
}

Lo que decimos se confronta con la funcionalidad de las instituciones si aceptamos que en sus espacios de funcionamiento social siempre hay intersticios para otras dinámicas, como la de la praxis humana, que "somete al conjunto de las instituciones funcionales a finalidades ya no funcionales" a partir de imponer, como sostiene Castoriadis, "significaciones sociales", respecto de las cuales la sociedad, por lo general, "está dispuesta a vivir y a morir por ellas" (Castoriadis, 2004: 25). ${ }^{7}$ La realidad como espacio de relaciones entre sujetos se concreta en momentos con dinámicas heterogéneas, con tiempos y espacios que no pueden reducirse a factores, por lo que debemos cuidarnos de no convertir el momento en causa, porque contiene muchas posibilidades de causas según sea el modo de concreción de la articulación histórica, que es la condición necesaria del esfuerzo por conformar significados y darles inteligibilidad, lo que implica la idea de los espacios de posibilidades. Es la racionalidad de las necesidades del momento la que permite aproximarnos al carácter específico de las determinaciones. La perspectiva de la articulación es la que hace posible precisar la naturaleza que asumen las determinaciones, por eso es indispensable pensar desde la articulación abierta a su propia especificidad histórica. De no ser así, difícilmente se podría avanzar más allá de lo instituido sin recurrir a extrapolaciones desde lo

\footnotetext{
${ }^{7}$ Por ejemplo, acerca de la finalidad de las pirámides, Castoriadis sostiene, como [era] servir "al faraón... [poder] sobrevivir en la otra vida y tener con ella un lugar después de él" (Castoriadis, 2004: 25), lo que construye un imaginario que recuperamos como construcción de sujetos históricamente situados, pero que cumple la función de darle cohesión social a la sociedad. En efecto, "el imaginario social, en tanto instituyente, establece significaciones imaginarias sociales: dios, los dioses, los ancestros, etcétera. Estas significaciones imaginarias sociales están encarnadas en, instrumentadas por, instituciones: la religión, por cierto, pero no solamente. Instituciones de poder económico, familiar, el lenguaje mismo (Castoriadis, 2004: 26). En general, este imaginario que le da cohesión a la sociedad, que es una construcción del hombre para darle cohesión a la sociedad, define el marco de la dinámica a que está ceñido el gasto de las fuerzas productivas, como la construcción de catedrales, templos o mezquitas, como lo señala el propio Castoriadis.
} 
construido, las cuales pueden resultar falaces (Zemelman, 1992a y 1992b).

Lo que decimos se traduce en conexiones entre lo articulante y lo articulable en un momento dado. ¿Cuáles son los rasgos de lo articulante? Debemos remitirnos a lo magmático como reflejo de relaciones que expresan un conjunto de necesidades que están presentes en toda relación micro-social. Cualquier relación a escala macro-social da lugar a estructuras, ${ }^{8}$ que es en lo que consiste la idea de determinaciones pertinentes. En lugar de hablar de conceptos-identitarios, nos parece más relevante plantear la cuestión de lo inclusivo debido a que no remite exclusivamente a la idea de conjuntos. En la articulación del momento se plantea diferenciar entre el plano del funcionamiento objetivo - estructuras, instituciones- y el de la lógica de lectura por los distintos sujetos, de conformidad con sus necesidades de construcción en una dirección particular entre varias opciones. Ello lleva a incorporar la dimensión de lo político como capacidad para reconocer lo potenciable, y la voluntad de construcción y su influencia para transformar lo estructural en ámbito de sentido, lo que equivale a la transformación de lo externo en experiencia de posibilidades. ${ }^{9}$ Es la historización de la historia. De ahí la conveniencia de trabajar con un concepto de objetividad conformado por la relación entre regularidades empíricas con voluntades sociales. Es lo que define la naturaleza particular del análisis de coyuntura que aborda el momento desde

\footnotetext{
8 "El capitalismo no son las fábricas, las computadoras, etc., en tanto tales..., sino que el capitalismo es aquello que, detrás de todos esos objetos, estas actividades, estas reglas legales o de hecho, etc., anima y empuja, y, por ejemplo, conduce a la producción que siente de una cantidad de 'cosos'... siempre más potente" (Castoriadis, 2004: 34). "Coso" es un objeto que no se conoce o que no se quiere o no se puede nombrar.

${ }^{9}$ Se plantea la dimensión de lo político, ya que, según W. Rathenau, "toda la realidad deviene en política cuando es pensada desde el futuro" (citado en Zemelman, 1989: 89). Se coloca en el centro del debate "la necesidad de lo político, en el marco, según G. Sartori, 'de que el mundo del hombre es infinitamente manipulable...”. Pero surge la pregunta: “¿cuáles son los límites de esta modalidad de la realidad histórica? ¿Cómo caracterizar esta necesidad de lo político?" (Zemelman, 1989: 82).
}

lo dado sin perder la perspectiva de que es parte de una secuencia que lo incluye.

Resulta claro que lo dicho plantea que la formación del pensamiento se concibe como el desarrollo, primero, de la necesidad y, después, de la capacidad para reconocer campos de despliegue que se transformen en opciones de sentido. La formación se refiere por tanto a la capacidad para desplegarse como sujeto en condiciones de posibilidades que sean desafíos para su movimiento, por eso el autoconocimiento - individual y social- se corresponde con la creación de condiciones de posibilidad que comprometen al conjunto de las facultades del hombre (Steiner, 1999). Ello requiere de lenguajes que muestren la necesidad de nuevos predicados pero sin anticiparlos. Por ese motivo, tenemos que revisar el concepto de realidad, en razón de que deja de ser una mera externalidad reducida a un conjunto de objetos que, al estar disociados del sujeto, cumplen la función de objetivación pero desligados de las posibilidades de despliegue del mismo. La forma del pensar histórico reconoce un espacio en las relaciones entre razón, imaginación e intuición, esto es, con todo el sujeto, tal como pretendía Dilthey. La colocación reemplaza la idea de objeto delimitado por la de espacios de posibilidades, el momento rompe con la idea de contenidos que sean función de determinaciones particulares para hacerlos parte de una articulación, lo constituyente subordina la exigencia de estructura-causa en tanto invariante a lo necesario que puede estar abierto a muchas formas, y por último la apertura trasciende lo establecido en términos de identidad para hacer posible el pensamiento desde lo indeterminado que rebasa los límites de lo dado.

En esta perspectiva, abordamos los desafíos del pensar histórico para hacernos cargo de sus exigencias categoriales tomando como base el movimiento de la subjetividad. Desde esta base se complejiza la relación de objetivación hacia lo externo en la medida en que cumple la función de delimitar espacios para el sujeto, de manera que la construcción de contenidos se traduce en posibilidades históricamente 
viables, lo que plantea tomar conciencia del sentido que permanece oculto en lo que decimos, o bien, que está subordinado a las lógicas dominantes. El movimiento de la subjetividad se traduce en cierta inconformidad con lo dado, pero no se agota en sí mismo, pues se acompaña de la voluntad de construir, aunque sin reducciones a proyecciones subjetivas y tampoco siendo un extravío a partir de especulaciones teóricas, como ha ocurrido con premisas y con el pensamiento crítico. Lo que se produce desde este movimiento de la subjetividad es la búsqueda de lo magmático y lo emergente antes que registrar la simple contratación de regularidades, porque la historicidad plantea que la realidad es un concepto de espacios de posibilidades que dan sentido a la capacidad de construcción de la práctica humana, lo que concuerda con un concepto des-ontologizado de ésta en la medida en que deviene en lo que hacemos con otros o lo que otros hacen, pero en una simultaneidad de direcciones, de tiempos y espacios.

\section{Conciencia histórica como premisa del pensamiento: implicaciones}

Hemos procurado poner de relieve una forma de razonamiento que puede dar cuenta no sólo de las regularidades, sino de las emergencias de los fenómenos sociales. De un modo o de otro, tiene que reflejarse en el lenguaje que ha sido reducido a compartimentos estancos, como la disciplina, concordante con la fragmentación del propio sujeto pensante. Recién ahora:

comenzamos a ser conscientes de que la separación entre religión, arte y filosofía, y tal vez, incluso la [existente] entre ciencia y filosofía, no es común a todas las culturas desde su propio carácter, sino que ha marcado la historia específica del mundo occidental (Gadamer, 2002: 234).

Resumimos el problema en formulaciones que es necesario definir como centro del acto de pensar para una visión, epistémica, orientada a la reconstrucción de procesos que pueda traspasar los límites de los esquemas explicativos y que subordine, además, cualquier constructo teórico con pretensión de universalidad a formas de razonamiento que den cuenta de la gestación de ideas desde la propia historicidad de los fenómenos, y plantear un cambio en la naturaleza de las premisas desde las que se organiza el pensamiento. Lo anterior plantea colocar como eje central del pensamiento a la conciencia histórica, que, como modalidad del pensamiento categorial, pone en el centro del debate la necesidad de potenciar al sujeto, no como exigencia ética, sino epistémica. Ello se traduce en los planos en que se desenvuelve la potenciación: la capacidad del sujeto para potenciar la externalidad, que a la vez no se resuelve sin la potenciación del sujeto desde sí mismo. Esto es, hay que abordar el doble movimiento que plantea la potenciación: el movimiento posible de activarse en lo real-externo y el movimiento interno, como la capacidad del hombre para intervenir en su realidad contextual.

En este marco, la conciencia histórica plantea exigencias como las siguientes: i) necesidad de sentido, en oposición a invitarnos a definir objetos; ii) reconocimiento de espacios para el sujeto, en vez de restringirse a construir una función puramente cognitiva; iii) construcción de opciones, en lugar de ceñirse a contenidos estrictamente disciplinarios, y iv) fundamentación en la categoría de potenciación, y no desde la determinación-explicación. Las preguntas han de responder a la colocación en el momento y en consecuencia a la apertura de los límites de lo dado, en la medida en que éstas buscan organizar al pensamiento desde el desafío de lo potencial que excede los límites que fijan el rigor de la inteligencia analítica. En consecuencia, la formulación de las preguntas tiene que recuperar la disyuntiva: a) no formularse en términos de objetos, sino de horizontes; $b$ ) no responder a requerimientos de explicación, sino de lo necesario, y c) no restringirse a una función de apropiación-control, sino de colocación. Reconocemos las modalidades siguientes: 
1) Preguntas que incorporan posibilidades de lo dado, en cuanto la denotación se construye desde la colocación. En efecto, se trata de hacer presente la incorporación de las significaciones históricas, lo que no se puede resolver sino es desde una necesidad existencial de historizarse, que no puede ser sólo una simple percepción del sujeto para que tenga una presencia significativa en la pregunta, sino que requiere de una determinada visión de futuro, escatología o utopía secularizada, condición para que la pregunta dé cuenta de los ámbitos que puedan convertirse en experiencias.

2) Preguntas que se abren a situaciones contextuales inclusivas, de modo que el contenido deviene en una expresión particular de una necesidad más amplia, a manera de ir tomando como referencia el contorno. Se plantea el reconocimiento de lo inacabado en tanto manifestación de secuencias, para denotar lo dado como posibilidad, así que el significado resulta un recorte de la potencialidad concebida desde la relación enhay que problematizar los significados dadosestablecidos tanto en el plano teórico como en el histórico, pues en cualquier construcción de significado habrá que reconocer los parámetros configuradores de lo dado.

Ambas modalidades de preguntas traducen una virtualidad que se especifica, epistémicamente, en la relación hombre-mundo: pensar con los otros, desde los otros, con los otros, ante los otros, por los otros, para los otros, y/o contra los otros, lo que constituye modalidades de la historicidad según como se presente en el sujeto que piensa. Tiene consecuencias en la gramática de la construcción de enunciados en tanto que apunta a un concepto de realidad como construcción y auto-construcción desde una red compleja de relaciones. De esta manera, las preguntas son parte del proceso de pensar: se parte de la colocación del sujeto (situación 1), seguido de la organización de la apertura (situación 2), a fin de dar lugar a un razonamiento que supere las

limitaciones de la "preocupación por el conocimiento conocido", en la terminología de Heidegger, que restringe las preguntas por la verdad "a la preocupación por la certeza".

\section{PENSAR ENVERBO: CONTENIDOSY TRASCENDENCIAS NECESARIAS}

Lo dicho representa un esfuerzo para superar las tendencias mecánicas y clasificatorias que aprisionan el pensamiento en el lenguaje de la lógica proposicional. Para liberarlo es indispensable que la argumentación "no inmovilice nuestro pensamiento inquisitivo e imprescriptivo", en términos de incuestionabilidad, remontándonos "más atrás de lo que se puede formular en un enunciado válido" (Gadamer, 2002: 238). Preguntar fuera de los límites de la lógica de validez e incuestionabilidad vincula el pensamiento con las necesidades de una situación histórica vasta y compleja, como una época, y plantea distinguir entre lo que necesitamos decir y la forma de decirlo. ¿De dónde procede esta necesidad mediada por conceptos? ¿Qué se oculta detrás de éstos? ¿Qué se arrastra como herencia en las palabras que empleamos?

Lo primero es reconocer los significados que se mantienen vivos en el lenguaje como esa "nubosidad de un significado, fijado en la convención de una buena expresión polivalente [que] hace hablar simultáneamente en el trasfondo los significados concomitantes, e inherentes a las palabras" (Gadamer, 2002: 240). A este respecto cabe señalar cómo la seducción por ganar precisión y rigor en el uso del lenguaje terminó por empobrecerlo. La dinámica de las palabras se pierde cuando se afirma que "las ciencias se refieren a la abstracción [pero] no hay actividad en ellas" (Suzuki, 1998: 21), que se relaciona con el hecho de que la ciencia - por lo menos en Occidente- "prospera con el dualismo", en la medida en que los científicos tratan de "reducirlo todo a medidas cuantitativas" y rechazan lo que no pueda sujetarse a este procedimiento. 
Es congruente lo que sostenemos con las formas dicotómicas de pensar con todas sus implicaciones culturales. Es así como se ha señalado que "Occidente, sí es sí y no es no; sí nunca puede ser no o viceversa", mientras que "Oriente hace que el sí se deslice hacia el no y el no hacia el sí. Es la naturaleza de la vida la que es así" (Suzuki, 1998: 18). Aunque lo más importante es la presencia del sujeto: en Oriente "lo que se espera de nosotros es que captemos al observador mismo como persona y no como algo que salga de él” (Suzuki, 1998: 55). En contraste, en Occidente la separación tajante del sujeto respecto de su discurso lo reduce a lo instrumental, en cuyo marco lo que cuenta es la eficacia operativa sin importar el sujeto, el cual en el mejor de los casos se reduce a las facultades mejor relacionadas con sus capacidades de procesar información y acción.

Subyace la posibilidad de pensar o no en verbo, que se corresponde en el empleo del lenguaje de un sujeto activo con capacidad de develar no solamente lo claro y construido, sino capaz de dar cuenta del presente como momento de una secuencia que, en su devenir, se traduce en la exigencia de pensar y explorar lo dado como siendo. En definitiva, es lo que da sustento a la categoría de lo necesario abierta a su propio desenvolvimiento. En esta dirección, su comprensión se limita a una óptica existencial que refleja la aceptación de lo indeterminado como consecuencia de un movimiento de lo real, y por tanto del mismo hombre: la presencia de lo indeterminado obliga a un esfuerzo de articulabilidad que rompe con las prácticas que encuadran los espacios del pensamiento y que obligan a razonar todos los límites de una manera abierta. Por ello, cuando se piensa la necesidad desde lo dado incompleto, se abre el ángulo para pensar todas las necesidades de trascendencia, configurando lo real como lo que excede a lo fijado, y desde ahí nace la inconformidad que

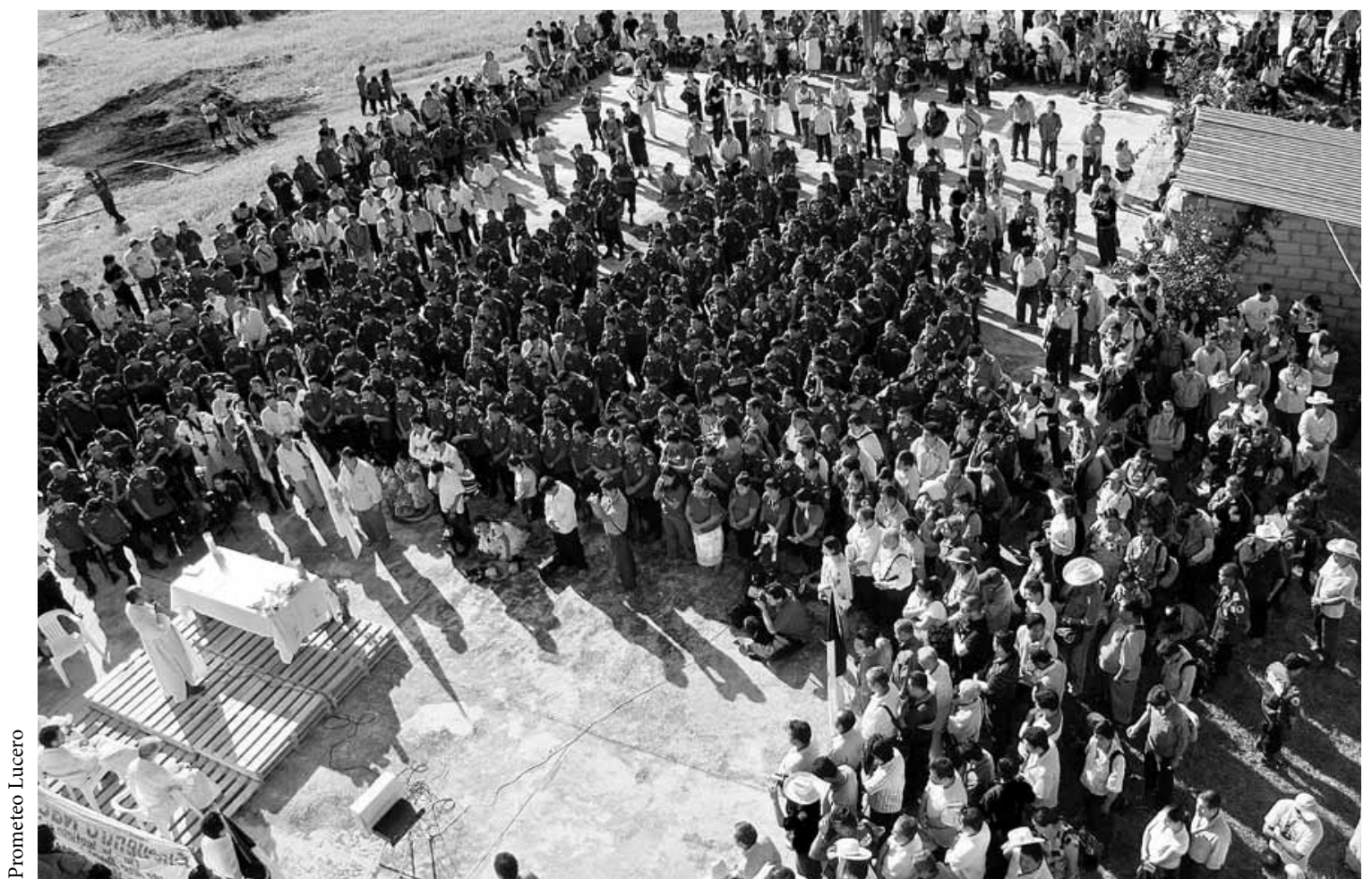

Desfile del aniversario de la Policía comunitaria, San Luis Acatlán, octubre de 2010. 


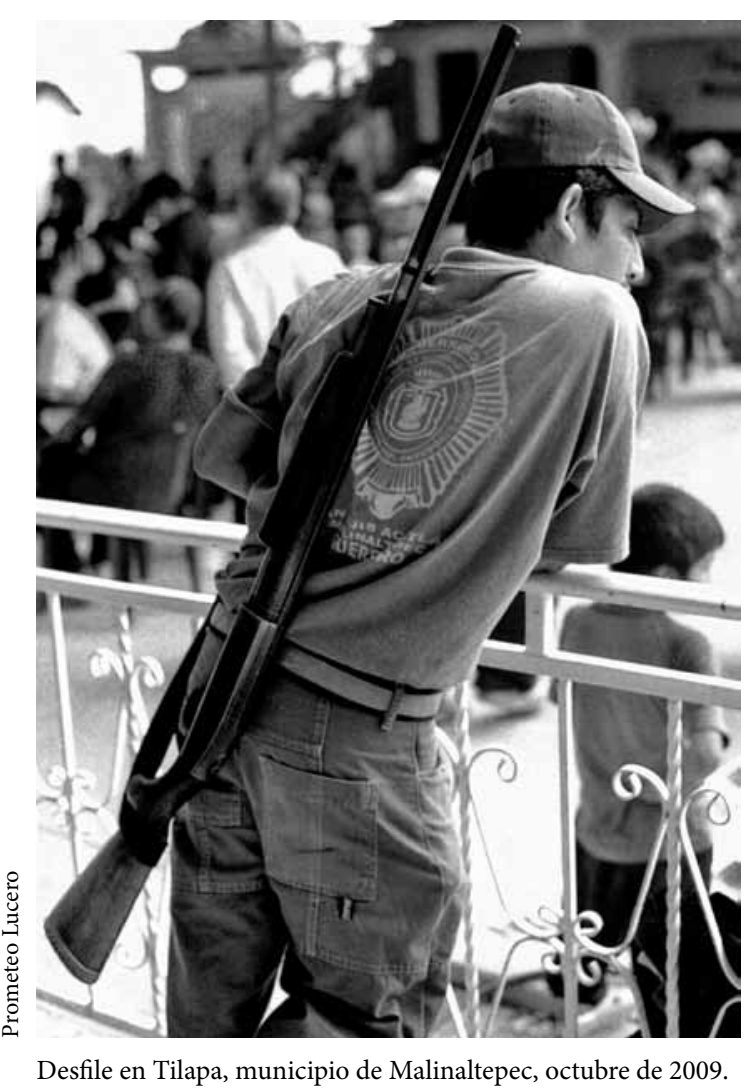

impulsa a la búsqueda de ideas que nos acechan y nos apremian a la vez. Es la función que cumple la configuración del contorno. ${ }^{10}$

Este problema puede describirse como la colocación ante lo que nos envuelve y que además fluye en forma de emergencias potenciales que pueden reconocer diferentes modos de concreción, en cuanto campo de experiencias posibles, de manera que "la

\footnotetext{
${ }^{10}$ Siempre estamos, conscientes o no, ante el desafío de no quedarnos aprisionados en los productos, en razón del movimiento tanto de la externalidad como del propio sujeto: "En su transcurrir existencial la condición humana está implicando ser una manifestación constante de lo transitorio que da primacía al siendo en el que se conjuga existencia e historia. Como tránsito la condición humana lleva a que el estar en determinadas situaciones alcance su realización en el estar-ante esas situaciones. Ello refleja la conciencia de la especificidad del momento que trasciende cualquier discurso sobre el mundo" (Zemelman, 2002: 91).
}

realidad" no puede pensarse sin "enlazar la objetividad objetiva con la voluntad de potenciación, produciéndose una articulación dinámica entre realidad, como externalidad, y la capacidad subjetiva del sujeto para construir sentidos" (Zemelman, 2002: 92). Se rompe con la lógica del objeto, ya que nos obligamos a estar por sobre el límite de lo dado, lo que lleva a pensar desde la colocación que rompe con el principio de determinación al apoyarse en lo más inclusivo que puede ser la época de un momento histórico dado, que trasciende con lo puramente cognitivo. Lo anterior supone convertir lo determinado en desafíos de nuevos espacios que cuestionen la lógica estructuradora del poder que busca transformar toda realidad en una situación fija y compacta. Se trata de ampliar la visión incorporando los contornos, cuya función es potenciar lo fragmentario desde las exigencias de la articulación abierta a lo indeterminado, lo que requiere de una articulación del conjunto de facultades del hombre, que Fromm define como "experiencia del hombre total".

El desafío en que pensamos constituía el papel de la filosofía, pero ahora, desde nuestra visión, es el lugar que ocupa la colocación ante las circunstancias. El discurso deviene en "la presencia de lo abarcable desde lo inabarcable, en forma de que eleve al sujeto y no lo atrape" (Zemelman, 2002: 36), y obliga a cuidarse de que el lenguaje no se limite a expresar la concreción tecnológica de la experiencia humana. Cuando se piensa lo real como mundo, lo importante no es la búsqueda de la verdad, sino de la necesidad de verdades, a modo de no caer aprisionado bajo el peso de las determinaciones dominantes que convertimos en parámetros. Lo que ha dejado de ocurrir en nuestra cultura es la argumentación que supone la centralidad del sujeto. ¿Cómo, entonces, recuperarlo? ¿Y cuál es el papel que cumplen los diferentes lenguajes, como los de la ciencia, la filosofía y el arte? ¿Se requiere, acaso, de una gramática que incorpore articuladamente las contribuciones singulares de los diferentes lenguajes? ¿Cuál es el significado de incorporar las metáforas al discurso, tal como han reclamado diversos autores, desde 
Nietzsche hasta Bachelard y Blumenberg, y como se registra en alguna medida en las investigaciones históricas?

Decimos que pensar en verbo se remite al modo de construir el ángulo como articulación dinámica para no incurrir en reduccionismos teóricos, pues no construye con base en determinaciones unívocas (Ortega y Gasset, 1937: 120), en la medida en que refleja la tensión entre determinación y apertura para vislumbrar nuevos campos de experiencias que den sentido al acto de pensar cuestionando lo dado. Son el ojo y el huracán como metáforas que aluden a la relación entre delimitación de objetos y su ubicación en los contornos que le dan significación desde su misma amplitud a lo que aparece como acotado, pero cuyo significado más profundo se resuelve en su articulación con aquello que lo contiene: con su propia apertura. De este modo, el pensamiento resulta de la colocación en un momento pero asumiendo la incompletud de lo dado en forma que los recortes de contenido puedan leerse a partir de la posibilidad que se contiene en su articulabilidad necesaria. Es el pensar abierto para resolver las exigencias de especificaciones nuevas. ${ }^{11}$ Por una parte, lo horizóntico se corresponde con una visión global conformada por un sentido valórico -horizonte capitalista, horizonte de la democracia-, mientras que lo inclusivo con la capacidad epistémica organiza el pensamiento sin apriorismos

\footnotetext{
${ }^{11}$ Podemos citar el comentario que hace Putnam de W. James acerca de la naturaleza de la objetividad: "las habas pueden describirse de casi infinitos modos distintos, dependiendo de los intereses de quien las describe, y cada una de las descripciones concretas corresponderán a las habas independientemente de la perspectiva de quien las describe, pero aun así reflejarán sus intereses" (Putnam, 1990: 50). De ahí que pudiendo reconocerse que "el mundo es como es independientemente de los intereses de quien lo describe", no puede ser "en una medida indeterminada, el producto de nuestras mentes", pero el problema no puede resolverse recurriendo a una "fantasía metafísica" (Putnam, 1990: 51). Se plantea la necesidad de aclarar que la cuestión no se reduce a un "producto de nuestras mentes", sino a reconocer que el despliegue de lo real desde una potencialidad conforme a un sentido de opciones de construcción es lo que está reñido con cualquier implicación metafísica.
}

teóricos, en tanto que lo indeterminado se corresponde con la capacidad de problematización de contenidos, debidamente clasificados, identificados, establecidos según exigencias de causa-efecto. Está claro que estamos invocando distintas dimensiones valóricas, ideológicas y analíticas, así como emocionales y volitivas, pero que son expresiones de la complejidad del sujeto.

Si el pensar histórico se desplaza hacia la articulación de niveles y momentos, este movimiento no puede ser el resultado de un razonamiento organizado desde premisas teórico-explicativas según un orden de factores. Antes bien, se trata de sentidos valóricos que condensan una necesidad de sentidos, cuya realización no se alcanza en una verdad incuestionable y con pretensiones de universalidad, sino al abrir espacios de construcción. En este caso, la potenciación puede plasmarse mediando un proyecto que pueda darle tangibilidad a la necesidad de pensar y conocer. La función del conocimiento es detectar nudos desde los que pueda intervenirse para potenciar lo dado en la dirección de sentido que se busca construir. En conclusión, se establece un vínculo entre el acto de pensar y el de asumirse como sujeto, entre conocer y auto-conocimiento, que es lo que marca la singularidad de convertir a la conciencia histórica en premisa desde donde organizar el pensamiento.

\section{Bibliografía}

Adorno, Theodor, 1984, Dialéctica negativa, Taurus, Madrid.

Berger, Peter, 1999, Risa redentora. La dimensión cómica de la experiencia humana, Kairós, Barcelona.

Bloch, Ernst, 2004, El principio esperanza, Trotta, Madrid. , 1983, Sujeto-objeto. El pensamiento de Hegel, Fondo de Cultura Económica, México.

Castoriadis, Cornelius, 2002, La insignificancia y la imaginación. Diálogos, conversaciones entre Castoriadis y Francisco Varela con Catherine Vonblow, Trotta, Madrid.

, 2004, Sujeto y verdad en el mundo histórico-social. La creación humana I, Fondo de Cultura Económica, México. 
Durant, Gilbert, 1999, Ciencia del hombre y tradición, Paidós, Barcelona.

Gadamer, Georg, 2001, El inicio a la sabiduría, Paidós, Barcelona.

lona.

Huidobro, Vicente, 2002, El ciudadano del olvido, Huerga y Fierro, Madrid.

Jullien, François, 2001, Un sabio no tiene ideas, Siruela, Madrid.

Marty, Eric, 2007, Roland Barthes, el oficio de escribir, Manantial, Buenos Aires.

Mondolfo, Rodolfo, [1954] 2004, Figuras e ideas de la filosofía del Renacimiento, Losada, Buenos Aires.

Nietzsche, Federico, 2010, Sobre el porvenir de nuestras escuelas, Tusquets, México.
Ortega y Gasset, José, 1937, El tema de nuestros tiempos, Cultura, Santiago de Chile.

Putnam, Hilary, 1990, Representación y realidad. Un balance crítico del funcionalismo, Gedisa, Barcelona.

Steiner, George, 1999, Heidegger, Fondo de Cultura Económica, México.

Suzuky, D. T. y Eric Fromm, 1998, Budismo zen y psicoanálisis, Fondo de Cultura Económica, México.

Zemelman, Hugo, 1989, De la historia a la política. La experiencia de América Latina, Siglo XXI, México.

- 1992a, Los horizontes de la razón I: dialéctica y apropiación del presente, Anthropos, Barcelona.

- 1992b, Horizontes de la razón II: historia y necesidad de utopía, Anthropos, Barcelona.

, 2002, Necesidad de conciencia. Un modo de construir conocimiento, Anthropos, Barcelona. 